\title{
HUBUNGAN KEPEMIMPINAN, MOTIVASI DAN LINGKUNGAN KERJA DENGAN KINERJA PEGAWAI
}

Mokh.Firman Ismana*, Tita Roosdiana**

\begin{abstract}
ABSTRAK
Berdasarkan data hasil pencapaian Badan Pengelolaan Lingkungan Hidup (BPLH) Kabupaten Majalengka pada bulan Desember tahun 2013, pencapaian di beberapa program masih di bawah target, program pelayanan administrasi perkantoran baru tercapai $89,35 \%$ dari target $100 \%$, program pengendalian pencemaran dan kerusakan lingkungan baru tercapai $91,37 \%$ dari target $100 \%$, serta dan program pengembangan kinerja pengolahan persampahan baru tercapai $82,28 \%$ dari target $100 \%$, hal ini merupakan salah satu indikasi belum optimalnya kinerja pegawai. Kinerja pegawai berhubungan dengan berbagai hal, diantaranya faktor kepemimpinan, motivasi dan lingkungan kerja. Tujuan penelitian ini adalah untuk mengetahui hubungan kepemimpinan, motivasi dan lingkungan kerja dengan kinerja pegawai BPLH Kabupaten Majalengka Tahun 2014.Jenis penelitian yang digunakan adalah penelitian analisis deskriptif analitik. Rancangan dalam penelitian ini adalah Cross sectional . Populasi penelitian ini adalah seluruh Pegawai Negeri Sipil BPLH Kabupaten Majalengka dengan sampel sebanyak 93 orang. Pengumpulan data dilakukan dengan tehnik angket menggunakan alat kuesioner, data yang terkumpul diolah dengan menggunakan program SPSS, data dianalisis dengan analisis univariat dan analisis bivariat yaitu untuk melihat hubungan antara dua variabel yaitu variabel dependen dan variabel independen. Analisis univariat didapatkan hasil bahwa kepemimpinan dinyatakan baik $(51,6 \%)$, motivasi dinyatakan baik $(57,0)$, dan lingkungan kerja dinyatakan baik $(55,9 \%)$. Analisis bivariat dilakukan dengan uji statistik Chi-square dengan batas kemaknaan $(\alpha)=0,05$. Hasil uji statistik didapatkan bahwa variabel motivasi $(p=0,007)$ dan lingkungan kerja $(p=0,005)$ mempunyai hubungan yang signifikan dengan kinerja pegawai sedangkan variabel kepemimpinan $(\mathrm{p}=0,116)$ tidak memiliki hubungan yang signifikan dengan kinerja.
\end{abstract}

Kata kunci $\quad$ : Kepemimpinan, Motivasi, Lingkungan Kerja dan Kinerja

\begin{abstract}
Based on the achievement data from Badan Pengelolaan Lingkungan Hidup ( BPLH ) Kabupaten Majalengka in December of 2013 , the achievement in some programs still below the target, program office administrative services only reached $89.35 \%$ of the target of $100 \%$, pollution control and environmental damage programs reached $91.37 \%$ of the target of $100 \%$, as well as program development and performance of waste processing reached $82.28 \%$ of the target of $100 \%$, this is one indication of the employee's performance is not optimal. Employee performance related to a variety of things, including the factors of leadership, motivation and work environment. The purpose of this study was to determine the relationship of leadership, motivation and work environment with Employee performance in BPLH Kabupaten Majalengka Tahun 2014. This type of research is descriptive quantitative research analysis.The design of this study was cross-sectional. The study population was all Civil Servants in BPLH Kabupaten Majalengka with a sample of 93 people. The data was collected using a questionnaire technique, the collected data were processed using SPSS version 17 and analyzed with univariate and bivariate analysis to look at the relationship between two variables: the dependent variable and the independent variables . Univariate analysis showed that leadership is expressed well (51.6\%), the motivation expressed either $(57.0 \%)$, and otherwise good working environment $(55.9 \%)$. Bivariate analysis performed by Chi-square statistical test with a significance limit $(\alpha)=0.05$. Statistical test results showed that motivational variables $(p=0.007)$ and work environment $(p=0.005)$ had a significant relationship with employee performance while the leadership variable $(p=0.116)$ had no significant relationship with employee performance.
\end{abstract}

Keywords : Leadership. Motivation, work Environment and Performance

\footnotetext{
* Staf Pengajar Program Studi S1 Kesehatan Masyarakat STIKes Cirebon

**Alumni PSKM STIKes Cirebon Lulus Tahun 2014
} 


\section{PENDAHULUAN}

Peranan Sumber Daya Manusia (SDM) merupakan salah satu faktor yang sangat penting dalam suatu organisasi. Pemanfaatan SDM secara efektif merupakan jalan bagi suatu organisasi untuk mempertahankan kelangsungan hidup dan pertumbuhan di masa yang akan datang. Dengan kata lain, kekuatan organisasi ditentukan oleh orang-orang yang mendukung organisasi tersebut, baik pada tingkat atas, menengah maupun tingkat bawah. Pada dasarnya organisasi bukan saja mengharapkan SDM yang mampu, cakap dan terampil, tetapi yang terpenting mereka mau bekerja giat dan berkeinginan untuk mencapai hasil kerja yang optimal. Kemampuan, kecakapan, dan keterampilan SDM tidak ada artinya bagi organisasi, jika mereka tidak mau bekerja dengan keras dengan menggunakan kemampuan, kecakapan dan ketrampilan yang dimilikinya. Apabila orang-orang tersebut bekerja secara profesional sesuai dengan kemampuan dan keahliannya yang dipengaruhi oleh motivasi mereka, maka organisasi akan mencapai tujuannya. ${ }^{1}$

Sumber daya manusia yang dimiliki oleh instansi pemerintah memiliki kemampuan berkembang tanpa batas, kemampuan ini dapat ditingkatkan dengan kepemimpinan yang baik, pemberian motivasi yang tepat dan menciptakan lingkungan kerja yang nyaman dan mendukung. ${ }^{1}$

Untuk mencapai tujuan organisasi kinerja pegawai harus optimal, kinerja adalah penampilan hasil karya personel baik kuantitas maupun kualitas dalam suatu organisasi apabila kinerja pegawai kurang baik maka pencapaian tujuan organisasi akan terhambat. ${ }^{1}$

Badan Pengelolaan Lingkungan Hidup (BPLH) mempunyai tugas pokok melaksanakan penyusunan dan pelaksanaan kebijakan daerah bidang lingkungan hidup. Dalam pelaksanaan tugas pokok dan fungsinya BPLH Kabupaten Majalengka didukung oleh SDM dari berbagai disiplin ilmu. BPLH memiliki 1 Bagian Kesekretariatan dan 3 Bidang yaitu Bidang Pengendalian Kerusakan Lingkungan Hidup, Bidang Pelestarian Lingkungan Hidup dan Bidang Pengelolaan Persampahan dan Kebersihan. ${ }^{2}$

Berdasarkan data pada bulan Desember tahun 2013 menunjukkan pencapaian hasil beberapa program masih berada di bawah target diantaranya program pelayanan administrasi perkantoran baru tercapai $89,35 \%$ dari target $100 \%$, program pengendalian pencemaran dan kerusakan lingkungan baru tercapai $91,37 \%$ dari target $100 \%$, dan program pengembangan kinerja pengolahan persampahan baru tercapai $82,28 \%$ dari target $100 \%{ }^{2}$

Berdasarkan hasil penelitian terdahulu, kinerja pegawai berhubungan dengan beberapa faktor diantaranya faktor kepemimpinan, motivasi, lingkungan kerja, pelatihan, kompensasi dan budaya kerja. ${ }^{3}$ Berdasarkan studi pendahuluan yang dilakukan oleh penulis permasalahan yang dihadapi di kantor BPLH diantaranya pegawai tidak memanfaatkan jam kerja yang ada, bahkan cenderung untuk mengurangi jam kerja dan kurangnya fasilitas penunjang kerja yang dirasakan oleh pegawai sehingga menggangu kinerja. Tujuan penelitian adalah untuk mengetahui hubungan kepemimpinan, motivasi dan lingkungan kerja dengan kinerja pegawai badan pengelolaan lingkungan hidup kabupaten majalengka tahun 2014.

\section{METODE PENELITIAN}

Jenis penelitian yang digunakan dalam penelitian ini adalah penelitian analisis deskriptif korelatif dengan pendekatan kuantitatif. ${ }^{4}$ Rancangan penelitian yang digunakan adalah rancangan cross sectional atau potong lintang. ${ }^{5}$ Variabel bebas pada penelitian ini adalah kepemimpinan, motivasi dan lingkungan kerja dan variabel terikat dalam penelitian ini adalah kinerja pegawai.

Populasi adalah seluruh pegawai negeri sipil BPLH Kabupaten Majalengka yang berjumlah 93 orang. Pengambilan sampel dengan sampling jenuh (semua populasi dijadikan sampel). Untuk mengetahui hubungan kepemimpinan, motivasi dan lingkungan kerja fisik dengan kinerja pegawai menggunakan kuesioner sedangkan teknik pengumpulan data 
menggunakan angket. Analisis univariat bertujuan untuk melihat gambaran dari setiap variabel. ${ }^{19}$ Analisis bivariat menggunakan Chi-square dengan batas kemaknaan $\alpha 0,05$.

\section{HASIL PENELITIAN}

\section{Kepemimpinan}

Hasil penelitian menunjukkan bahwa responden yang menyatakan kepemimpinan di BPLH Kabupaten Majalengka baik dengan persentase sebesar 51,6\% sedangkan responden yang menyatakan kepemimpinan kurang baik sebesar 48,4\%.

\section{Motivasi}

Hasil penelitian menunjukkan bahwa responden yang menyatakan motivasi pegawai di BPLH Kabupaten Majalengka baik dengan persentase sebesar 43,0\% sedangkan responden yang motivasinya kurang baik sebesar $57,0 \%$.

\section{Lingkungan Kerja}

Hasil penelitian menunjukkan bahwa responden yang menyatakan lingkungan kerja di BPLH Kabupaten Majalengka baik dengan persentase sebesar 55,9\% sedangkan responden yang menyatakan lingkungan kerja kurang baik sebesar $44,1 \%$.

\section{Kinerja}

Hasil penelitian menunjukkan bahwa responden yang memiliki kinerja baik dengan persentase sebesar 71,0\% sedangkan responden yang kinerjanya kurang baik sebesar 29,0\% .

\section{Hubungan Kepemimpinan dengan Kinerja}

Tabel 1 Hubungan Kepemimpinan dengan Kinerja Pegawai BPLH

\begin{tabular}{llcccccccc}
\hline \multirow{2}{*}{ No. } & Kepemimpinan & \multicolumn{3}{c}{ Kinerja } & \multicolumn{2}{c}{ Jumlah } & P-value \\
& & \multicolumn{2}{c}{ Kurang baik } & \multicolumn{2}{c}{ baik } & & & \\
& & $\mathrm{n}$ & $\%$ & $\mathrm{n}$ & $\%$ & $\mathrm{n}$ & $\%$ & \\
\hline 1. & Kurang baik & 17 & 37,8 & 28 & 62,2 & 45 & 100 & 0,116 \\
2. & Baik & 10 & 20,8 & 38 & 79,2 & 48 & 100 & \\
\hline & Jumlah & 27 & 29,0 & 66 & 71,0 & 93 & 100 & \\
\hline
\end{tabular}

Hasil uji statistik Chi-square diperoleh P-value 0,116 (>0,05) maka dapat disimpulkan bahwa tidak ada hubungan antara kepemimpinan dengan kinerja pegawai.

\section{Hubungan Motivasi dengan Kinerja}

Tabel 2 Hubungan Motivasi dengan Kinerja Pegawai BPLH

\begin{tabular}{|c|c|c|c|c|c|c|c|c|}
\hline \multirow[t]{3}{*}{ No. } & \multirow[t]{3}{*}{ Motivasi } & \multicolumn{4}{|c|}{ Kinerja } & \multicolumn{2}{|c|}{ Jumlah } & \multirow[t]{3}{*}{ P-value } \\
\hline & & \multicolumn{2}{|c|}{ Kurang baik } & \multicolumn{2}{|c|}{ baik } & \multirow[b]{2}{*}{$\mathrm{n}$} & \multirow[b]{2}{*}{$\%$} & \\
\hline & & $\mathrm{n}$ & $\%$ & $\mathrm{n}$ & $\%$ & & & \\
\hline 1. & Kurang baik & 18 & 45,0 & 22 & 55,0 & 40 & 100 & \\
\hline 2. & Baik & 9 & 17,0 & 44 & 83,0 & 53 & 100 & \\
\hline & Jumlah & 27 & 29,0 & 66 & 71,0 & 93 & 100 & \\
\hline
\end{tabular}

Hasil uji statistik Chi-square diperoleh P-value $0,007(\leq 0,05)$ dapat disimpulkan bahwa ada hubungan antara motivasi dengan kinerja pegawai. 


\section{Hubungan Lingkungan Kerja dengan Kinerja}

Tabel 3 Hubungan Lingkungan Kerja dengan Kinerja Pegawai BPLH

\begin{tabular}{|c|c|c|c|c|c|c|c|c|}
\hline \multirow[t]{3}{*}{ No. } & \multirow{3}{*}{$\begin{array}{l}\text { Lingkungan } \\
\text { Kerja }\end{array}$} & \multicolumn{4}{|c|}{ Kinerja } & \multirow{2}{*}{\multicolumn{2}{|c|}{ Jumlah }} & \multirow[t]{3}{*}{ P-value } \\
\hline & & \multicolumn{2}{|c|}{ Kurang baik } & \multicolumn{2}{|c|}{ baik } & & & \\
\hline & & $\mathrm{n}$ & $\%$ & $\mathrm{n}$ & $\%$ & $\mathrm{n}$ & $\%$ & \\
\hline 1. & Kurang baik & 19 & 46,3 & 22 & 53,7 & 41 & 100 & \\
\hline 2. & Baik & 8 & 15,4 & 44 & 84,6 & 52 & 100 & \\
\hline & Jumlah & 27 & 29,0 & 66 & 71,0 & 93 & 100 & \\
\hline
\end{tabular}

Hasil uji statistik Chi-square diperoleh P-value 0,002 $(\leq 0,05)$ dapat disimpulkan bahwa ada hubungan antara lingkungan kerja dengan kinerja pegawai.

\section{PEMBAHASAN}

\section{Hubungan Kepemimpinan dengan Kinerja}

Berdasarkan analisa penulis dengan menggunakan uji statistik Chi-square dengan batas kemaknaan $\alpha=0,05$ melalui SPSS diperoleh nilai P-value 0,116 yang artinya tidak ada hubungan antara kepemimpinan dengan kinerja pegawai. Hasil penelitian ini tidak sesuai dengan penelitian yang telah dilakukan oleh Joko Purnomo tahun 2007, yang memperoleh hasil bahwa kepemimpinan berpengaruh terhadap kinerja pegawai. ${ }^{3}$

Hasil penelitian menyatakan bahwa tidak ada hubungan antara kepemimpinan dengan kinerja pegawai, asumsi penulis mengenai hasil penelitian ini yaitu hal ini dimungkinkan karena pegawai sudah melaksanakan fungsi dan tanggungjawabnya dengan pengawasan yang melekat pada setiap pekerja telah berjalan dengan baik. ${ }^{6}$

\section{Hubungan Motivasi dengan Kinerja}

Berdasarkan analisis data menggunakan uji statistik Chi-square dengan batas kemaknaan $\alpha=0,05$ melalui SPSS diperoleh nilai P-value 0,007 yang artinya ada hubungan yang signifikan antara motivasi dengan kinerja pegawai. Hasil penelitian ini sesuai dengan penelitian yang telah dilakukan oleh Farhatin Ladia di Direktorat Pendidikan Madrasah tahun 2009, yang memperoleh hasil bahwa variabel motivasi memiliki hubungan yang signifikan dengan kinerja pegawai. ${ }^{7}$

Motivasi merupakan kondisi atau energi yang menggerakan diri karyawan yang tertuju untuk mencapai tujuan organisasi, sikap mental yang pro dan positif terhadap situasi kerja itulah yang memperkuat motivasi kerjanya untuk mencapai kinerja maksimal. ${ }^{6}$ Motivasi adalah salah satu dari variabel psikologis, variabel tersebut mempengaruhi perilaku kinerja yang pada akhirnya berpengaruh pada kinerja personel. ${ }^{6}$

\section{Hubungan Lingkungan Kerja dengan Kinerja Pegawai BPLH}

Berdasarkan analisa penulis dengan menggunakan uji statistik Chi-square dengan batas kemaknaan $\alpha=0,05$ melalui SPSS diperoleh nilai P-value 0,002 yang artinya ada hubungan yang signifikan antara lingkungan kerja dengan kinerja pegawai. Hasil penelitian ini sesuai dengan penelitian yang telah dilakukan oleh Vera Parlinda dan M.Wahyudin diperoleh hasil bahwa pelatihan dan lingkungan kerja berpengaruh signifikan terhadap kinerja karyawan. ${ }^{3}$

\section{SIMPULAN}

Dari penelitian tentang kepemimpinan, motivasi, lingkungan kerja dan kinerja pegawai diperoleh hasil sebagai berikut: 
1. Kepemimpinan di BPLH Kabupaten Majalengka Tahun 2014 dinyatakan baik $(51,6 \%)$.

2. Motivasi pegawai di BPLH Kabupaten Majalengka Tahun 2014 dinyatakan baik (57,0\%).

3. Lingkungan kerja di BPLH Kabupaten Majalengka Tahun 2014 dinyatakan baik (55,9\%).

4. Tidak ada hubungan antara kepemimpinan dengan kinerja pegawai BPLH Kabupaten Majalengka Tahun 2014.

5. Ada hubungan antara motivasi dengan kinerja pegawai BPLH Kabupaten Majalengka Tahun 2014.

6. Ada hubungan antara lingkungan kerja dengan kinerja pegawai BPLH Kabupaten Majalengka Tahun 2014.

\section{SARAN}

1. Bagi Pegawai BPLH Kabupaten Majalengka

1) Pegawai diharapkan terus memotivasi diri untuk melakukan pekerjaan dengan sebaikbaiknya agar kinerja meningkat.

2) Pegawai diharapkan dapat bekerja sama dengan baik, dengan sesama pegawai dan dengan pimpinan agar lingkungan kerja kondusif.

2. Bagi pimpinan BPLH Kabupaten Majalengka

1) Pimpinan dalam organisasi hendaknya membuat kebijakan yang memberikan perhatian yang lebih terhadap aspek motivasi misalnya dengan melakukan pendekatan kepada pegawai agar mengetahui kendala yang dirasakan pegawai saat melaksanakan pekerjaan, mengembangkan kemampuan pegawai sesuai dengan bidangnya, memberikan penghargaan kepada pegawai yang kinerjanya baik sehingga pegawai akan berusaha melakukan pekerjaan dengan sebaik-baiknya sehingga kinerja meningkat.

2) Pimpinan dalam organisasi diharapkan membuat kebijakan terkait lingkungan kerja, agar lingkungan kerja lebih baik lagi, dengan cara menambah fasilitas yang kurang lengkap dan memperbaiki serta memelihara fasilitas yang telah ada agar semua pegawai merasa nyaman dan tercipta suasana kondusif untuk melakukan pekerjaan dengan sebaik-baiknya.

\section{DAFTAR PUSTAKA}

1. Makalah pengaruh motivasi pegawai terhadap disiplin kerja di kecamatan X; [diakses tanggal 11 Desember 2013]. Diunduh dari:http://slideshare.net

2. Anonim. Laporan Realisasi Anggaran BPLH Kabupaten Majalengka; Majalengka :2013.

3. Risky Novianto A. Pengaruh kepemimpinan, motivasi dan lingkungan kerja fisik terhadap kinerja karyawan. Skripsi. Semarang: Undip;2011.

4. A.Aziz Alimul Hidayat. Metode penelitian kebidanan dan teknik analisis data. Jakarta: Salemba Medika;2007.

5. Yaslis Ilyas. Kinerja (teori, penilaian dan penelitian). FKMUI: Pusat Kajian Ekonomi Kesehatan;2002.

6. Sugiyono. Metode Penelitian kuantitatif, kualitatif dan R\&D. Bandung: CV.Alfabeta; 2009.

7. Farhatin Ladia. Pengaruh motivasi dan budaya kerja terhadap kinerja pegawai direktorat pendidikan madrasah. Tesis. Depok: FISIP UI; 2009. 